\title{
LÉXICO E VERBETES DA "ICONOLOGIA DEL Cavaliere Cesare Ripa Perugino" - SUAS TRADUÇÕES PARA FINS DIDÁTICOS
}

\author{
Lessico e lemmi dell" "Iconologia del Cavaliere Cesare \\ Ripa Perugino" - le sue traduzioni per fini didattici
}

\section{Lexicon and entries of "Iconologia del Cavaliere Cesare RipaPerugino" - Translations for didactic purposes}

\author{
Carlos Perini* \\ Maryelle Cordeiro** \\ SORAYA COPPOLA ** \\ DAVI FARACE $* * *$
}

RESUMO: Este trabalho apresenta a metodologia de tradução da obra "Iconologia del Cavaliere Cesare Ripa Perugino", bibliografia basilar para as áreas de Linguística, Letras e Artes, e para as Humanidades, que é proposta através de glossários temáticos, inseridos por tabelas com explicação detalhada sobre cada termo elucidado, nos quais são construídos curiosos estudos da iconologia nos séculos XVI e XVII, personificando conceitos em alegorias, associando posturas e costumes à moral e à indumentária daquele tempo. A tradução, acompanhada do estudo sobre a origem de termos e da iconografia associada, possibilita novas criações linguísticas e artísticas. O público-alvo dessa obra era a alta sociedade da época, com o uso de léxico diversificado e de difícil entendimento, por vezes, em latim ou grego. Antes de realizar a tradução do texto, foi necessário o conhecimento de noções de paleografia, pois a escrita de Ripa diferencia-se da atual pela grafia de certas palavras, regras de uso de letras maiúsculas e acentuação. A tradução permite verificar interessantes aspectos da língua, sincrônica e diacronicamente. A análise do texto permite, além de pesquisas linguísticas, iconológicas e iconográficas, a realização de estudos literários, pois o conteúdo da obra se configura como uma base cultural, imagética e histórica que retrata a vida no século

\footnotetext{
*Universidade Federal dos Vales do Jequitinhonha e Mucuri (UFVJM) carlos.perini@gmail.com (ORCID: 0000-0003-1988-0653)

**Universidade Federal de Minas Gerais (UFMG)

maryellecordeiro@gmail.com (ORCID: 0000-0003-4459-4675)

***Universidade Federal de Minas Gerais (UFMG)

socoppola@gmail.com (ORCID: 0000-0002-8285-4274)

**** Universidade Federal de Minas Gerais (UFMG)

davicinemaufmg@gmail.com (ORCID: 0000-0003-2652-8260)

DOI: http://dx.doi.org/10.11606/issn.2238-8281.v0i40p127-143
}

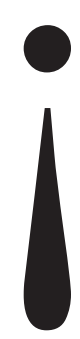


XVII. Finalmente, o trabalho de tradução da obra mostra-se extremamente enriquecedor, sobretudo pela seleção lexical traduzida didaticamente, pensando os equivalentes culturais no tempo-espaço e na nomeação dos acessórios e vestimentas daquela época em relação à contemporaneidade.

PALAVRAS-CHAVE: Léxico histórico; Tradução; Material didático; Iconografia; Século XVII.

ABSTRACT: Questo lavoro presenta la metodologia di traduzione dell'opera "Iconologia del Cavaliere Cesare Ripa Perugino", bibliografia di base per la Linguistica, per le Lettere e per le Arti e per le discipline umanistiche, che viene proposta attraverso glossari tematici, inseriti in tabelle con una spiegazione dettagliata di ciascun termine delucidato, in cui si costruiscono curiosi studi di iconologia nei secoli XVI e XVII, personificando concetti in allegorie, associando posture e costumi con la morale e l'abbigliamento di quel tempo. La traduzione, accompagnata dallo studio dell'origine dei termini e dell'iconografia associata, consente nuove creazioni linguistiche e artistiche. Il pubblico di riferimento di quest'opera era l'alta società dell'epoca, con l'uso di un lessico diversificato e di difficile comprensione, a volte in latino o in greco. Prima di effettuare la traduzione del testo, è stato necessario avere una conoscenza di nozioni di Paleografia, poiché la scrittura di Ripa differisce da quella attuale per l'ortografia di alcune parole, le regole d'uso delle lettere maiuscole e l'accentuazione. La traduzione consente di verificare aspetti interessanti della lingua, sia in modo sincronico che diacronico. L'analisi del testo consente, oltre alla ricerca linguistica, iconologica e iconografica, la realizzazione di studi letterari, poiché il contenuto dell'opera si configura come base culturale, immaginaria e storica che ritrae la vita nel Seicento. Infine, il lavoro di traduzione dell'opera si rivela estremamente ricco, soprattutto per la selezione lessicale tradotta didatticamente, considerando gli equivalenti culturali nel tempo-spazio e la denominazione degli accessori e degli abiti dell'epoca in relazione alla contemporaneità.

PAROLE-CHIAVE: Lessico storico; Traduzione; Materiale didattico; Iconografia; XVII Secolo.

ABSTRACT: This work presents the translation methodology of the work "Iconologia del Cavaliere Cesare Ripa Perugino", basic bibliography for the areas of Linguistics, Letters and Arts and the humanities, which is proposed through thematic glossaries inserted in tables, with detailed explanation about each term elucidated, in which curious studies of iconology in the 16th and 17th centuries are built, personifying concepts in allegories, associating postures and customs with the morals and clothing of that time. Translation, accompanied by the study of the origin of terms and associated iconography, enables new linguistic and artistic creations. The target audience for 
"Iconologia del Cavalier Cesare Rip Perugino" was the high society of the time, with the use of a diversified lexicon, at times difficult to understand, with words in Latin or Greek. Before carrying out the translation of the text, it was necessary to have knowledye of paleography, since Rip's writing differs from the current one in the spelling of certain words, rules of use of capital letters and accentuation. Translation allows us to investigate interesting aspects of the language, both synchronously and diachronically. In addition to linguistic research, the analysis of the text allows iconological, iconographic and literary studies, since the work presents cultural, imaginary and historical content that portrays life in the 17th century. Finally, translating the work proves to be extremely enriching, especially due to the lexical selection translated didactically, consicering the cultural equivalents in time and space and the naming of the accessories and clothing of that time in relation to contemporary times.

KEYWORDS: Historical lexicon; Translation; Didactic material; Iconography; XVII Century. 


\section{Introdução}

Cesare Ripa foi um erudito e literato italiano que viveu entre os anos 1560 e 1645. Passou a maior parte de sua vida em Roma, primeiramente, a serviço do cardeal Montelparo e, depois, da família Salviati.

Em 1593, em Roma, publicou a primeira edição da obra Iconologia del Cavalier Cesare Ripa Perugino. Ripa acompanhou as oito primeiras edições: Roma, 1593; 1603; Milão, 1602; Siena, 1613; Padova, 1611, 1618, 1625, 1630. As duas primeiras edições (Roma, 1593 e Milão, 1602) não apresentam imagens. As edições seguintes apresentam modificações textuais significativas, por correções e/ou acréscimos, feitas pelo próprio autor, num continuum de redação.

O original de Ripa (em diferentes publicações) se apresenta como fonte singular, na qual se verifica a presença de palavras e conhecimentos referentes aos costumes, à moral e às Belas Artes, bem como um léxico que engloba várias áreas afins. Sua singularidade se apresenta pela sua importância e referência para a sua época de publicação inicial.

A tradução objetivou realizar a descrição detalhada da obra que compilou conhecimentos daquele período, oportunizando aos interessados o acesso à tal cultura. A referida proposta vem sendo desenvolvida por meio de um percurso auto construtivo, no qual as fases executadas vão indicando os procedimentos necessários às fases consecutivas. O texto em processo de tradução é a última edição que foi feita em Veneza, em 1645, e contém uma quantidade significativa de ilustrações.

A catalogação visual, como uma ficha técnica especifica, é contribuição visionária de Ripa, cujo processo sistemático nos apresenta indicações significativas sobre o período em que viveu o autor. Confrontar as ilustrações descritivas de alegorias junto ao conteúdo textual que se desenvolve é propor uma leitura transversal entre imagem e texto.

O objetivo de Ripa, declarado no Proemio ai lettori, foi de ocupar-se do tipo de imagem "que pertence aos pintores, na verdade, àqueles que por meio de cores ou de outra coisa visível possam representar alguma coisa diferente dela"1 (RIPA, 1593, p. 9a).

Para o autor, as qualidades fundamentais que devem ter as figuras dos pintores são a "semelhança" e a correspondência com o texto de onde trazem inspiração:

[...] e a definição escrita, se bem se faça com poucas palavras, parece que deve ser esta em pintura, em imitação daquela, não é, no entanto, má a observação de muitas coisas propostas, para que das muitas se possam eleger as poucas, que façam mais à propósito, ou todas juntas façam uma composição que seja símile à descrição. (RIPA, 1593, p.9a). ${ }^{2}$

Os conhecimentos dos conceitos por meio das imagens simbólicas são, enfim, paragonados por Ripa:

1 Trecho original: “che appartiene a' Dipintori, ovvero a quelli, che per mezzo di colori, o di altra cosa visibile possono rappresentare qualche cosa differente da essa.” (aqui e, a seguir, as traduções são de nossa autoria): 2 "La definizione scritta, benchè si faccia di poche parole, e di poche parole par che debba essere questa in Pittura ad immitazione di quella, non è però male l'osservazione di molte cose proposte, acciocchè dalle molte si possano eleggere le poche, che fanno più a proposito, o tutte insieme facciano una composizione, che sia più simile alla descrizione." 
[...] a uma pessoa sábia, mas direcionada na solidão e nua por muitos anos, a qual, por andar onde está a conversação, se reveste, para que os outros, atraídos pela impressão exterior do corpo, que é a imagem, desejem entender minutamente aquelas qualidades, que dão esplendor à alma, que é a coisa significada. (RIPA, 1593, p.9a). ${ }^{3}$

A edição selecionada para a tradução, a de 1645, é uma obra publicada posteriormente à morte de Cesare Ripa Perugino e que tem como autores SS. Mauritio e Lazaro. Esta edição especificamente, encontrada na Biblioteca Nazionale di Napoli, reúne várias imagens e formas de representações antigas em um denso compêndio de 764 páginas e nos garante o texto de Ripa já concluído, apesar das falas dos autores que a propuseram.

As imagens da Iconologia da edição em estudo são elementos de inenarrável importância, por sua possibilidade de aproximação ou distanciamento com outras tantas imagens ilustrativas encontradas nas inúmeras publicações do texto, sendo, também, fonte de confronto com imagens das Artes, na qual as alegorias foram amplamente aplicadas da Antiguidade até o século XIX.

A obra se divide em três grandes livros: 01 - vocábulos de A a F; 02 - vocábulos de G a P; e 03 - vocábulos de Q a Z. Com a tradução, nos é, de fato, apresentado o distinto e detalhado estudo de Ripa. Deparamo-nos inicialmente com oito tabelas que contém, cada uma, um específico assunto que se desenvolve com itens colocados na sequência das letras correspondentes a todo o alfabeto ítalo-latino da época. Logo, tais tabelas organizam os vários conteúdos presentes na obra em itens para, posteriormente, o idealizador exemplificá-los e elaborar uma representação imagética e icônica de cada um.

O objetivo deste trabalho é apresentar uma proposta de tradução multidisciplinar e intermidial da obra, em língua italiana, Iconologia del Cavalier Cesare Ripa Perugino. Além disso, a partir da tradução do texto, pretende-se produzir material didático e permitir o acesso de alunos de cursos de graduação e pós-graduação, sobretudo das áreas de Linguística, Letras e Artes e de Ciências Humanas. Desse modo, os que utilizam a obra do autor como referência e fonte de pesquisa poderão ler os conhecimentos e saberes propagados pela obra, a fim de que sejam promovidas diversas frentes de pesquisa em que os elementos paratextuais possam ser confrontados e analisados em conformidade aos estudos comparativos sobre iconologia ao longo da História das Artes.

Cesare Ripa, por meio de sua densa e detalhada iconologia, nos permite ver e entender o passado de forma a estabelecer comparações e identificações com nosso presente. O literato escrevia para os poderosos da época, um público restrito, intelectual e acadêmico. Sua singularidade se apresenta pela sua importância e referência para a sua época de publicação inicial. Dessa forma, o trabalho de tradução em curso pretende realizar a descrição detalhada do compêndio que reuniu grande parte do conhecimento do século XVI, dando aos interessados a oportunidade de acesso a tal cultura.

3 "Una persona sapiente, ma versata nelle solitudini, e nuda per molti anni, laquale per andare dove la conversione si riveste, acciochè gl'altri allettati dalla vaghezza esteriore del corpo, che è l'imagine, desiderino d'intendere miratamente quelle qualità, che danno splendidezza all'anima, che è la cosa significata." 


\section{Fundamentação teórica}

Para a elaboração deste trabalho, apoiamo-nos nas noções de Paleografia de Berwanger e Leal (2008), nos Estudos da Tradução de Mounin (1975), nos Estudos do Léxico propostos por Biderman (1984, 2001) e Abbade (2012) e, por último, recorremos a Cantù (2011) e a Scrivener (2011) para a metodologia de produção de material didático e aplicações didáticas.

O primeiro passo para a tradução de qualquer texto começa pela leitura e compreensão, ou seja, pela decodificação dos caracteres que vemos diante de nossos olhos. Iconologia del Cavalier Cesare Ripa Perugino é uma obra publicada pela primeira vez em 1593, com sucessivas reedições. A versão com a qual trabalhamos é do ano de 1645, ou seja, temos um arco temporal que nos distancia de 375 anos. Nesse intervalo de tempo, a tipografia passou por diversas fases até chegar ao que conhecemos na contemporaneidade. Graças à padronização dos tipos móveis, hoje é possível que qualquer pessoa alfabetizada consiga pelo menos ler qualquer texto que esteja em sua língua. No entanto, no período que sucedeu à invenção da prensa móvel por Gutenberg, esses padrões ainda não estavam totalmente definidos e normalizados, sendo que muitas vezes imitavam os textos manuscritos, o que torna a leitura desses textos, hoje, um pouco mais dificultosa do que a leitura de um texto contemporâneo. Para auxiliar nessas leituras, recorremos às noções de Paleografia.

Segundo Berwanger e Leal (2008, p. 15), "Por Paleografia compreende-se o estudo da escrita antiga, conforme a etimologia grega da palavra: paleos (antiga) + graphein (escrita)." Nesse sentido, a Paleografia é uma disciplina histórica que estuda os registros escritos, ou seja, as características e evolução das primeiras formas de escrita. Em particular, consiste na capacidade de ler, interpretar e datar textos manuscritos e em saber reconhecer a autenticidade, além dos contextos socioculturais de seu uso. Para isso, tenta reconstruir a história das formas gráficas, fazer a sua decodificação, datação e localização, por meio do estudo de técnicas executivas e da comparação entre diferentes exemplos.

A Paleografia foi consagrada pelo beneditino francês, Jean Mabillon (1642-1707). Além do estudo dessa área do conhecimento, o estudioso também se dedicou à Diplomacia e à Cronologia. Inicialmente, a principal função desses estudos era jurídica, pois servia para comprovar a autenticidade de documentos e, dessa forma, conseguir provar o direito de uma pessoa sobre determinado patrimônio.

A principal contribuição da Paleografia para a história consiste na decodificação dos documentos manuscritos utilizados como fonte, embora os objetos diretos da disciplina sejam as práticas de escrita e a história do signo gráfico independentemente do seu conteúdo. O objetivo primordial da paleografia é estabelecer o tipo de texto de acordo com a área de uso e o tipo de escrita, além de definir sua data e local de origem. Muitas outras disciplinas lhe estão relacionadas ou dela fazem uso. Com relação ao texto de Cesare Ripa, nos interessa particularmente a Paleografia, haja vista que para realizar a leitura do texto é necessário ter algum conhecimento, ter noções de paleografia para que se possa entender o texto, ainda que não se trate de um texto 
manuscrito, pois alguns caracteres impressos são muito semelhantes aos caracteres manuscritos, o que dificulta a sua leitura.

Após a leitura e decodificação do texto, nos deparamos com a etapa da tradução. Não se trata apenas de traduzir o tex to do italiano para o português, mas de traduzir do italiano seiscentista para o italiano contemporâneo e posteriormente para o português.

Segundo Mounin (1975), o tradutor não deve conceber a tradução como uma simples operação linguística. Para ele, não é possível traduzir um texto de uma língua para a outra pensando somente em elementos gramaticais. Seria necessário, dessa forma, realizar também um estudo cultural relativo à língua da qual se está traduzindo um texto. O autor define a tradução como "uma operação sobre fatos a um só tempo linguísticos e culturais, mas cujos pontos de partida e de chegada são sempre linguísticos" (MOUNIN, 1975, p. 215). Nesse sentido, o estudioso explica que para se realizar uma tradução é necessário, além de conhecer a língua, conhecer igualmente as coisas a que o texto se refere.

Os conceitos de tradução de Mounin se relacionam diretamente com a tradução ora feita do texto de Ripa. Além de conhecer a língua na qual o texto foi escrito, também devemos conhecer um pouco sobre o contexto social daquela época. Com relação à língua, há de se levar em consideração que, no século XVI, a língua italiana como a conhecemos hoje ainda não existia, não era padronizada. Como aponta Cordeiro (2019, p.91), a propósito das diversidades linguísticas na península itálica no século XVI, era que:

[...] não existia até então uma variedade reconhecida como standard. Cada cidade tinha uma maneira própria de falar, muitas vezes incompreensível para aqueles que estivessem próximos, mas fora dos seus confins. (CORDEIRO, 2019 p.91)

Dessa forma, é possível perceber que, antes de realizar a tradução do italiano para o português, seria necessário conhecer não só a língua utilizada por Ripa, mas a cultura e os costumes daquela época, para que se pudesse dar prosseguimento à tradução do italiano contemporâneo para o português.

Com a tradução realizada, surge o texto com o qual pretendemos elaborar o material didático voltado para as áreas de artes e ciências humanas. Para isso, o primeiro elemento textual que surge, sendo extremamente rico e bem elaborado na obra, é o léxico.

Para Alinei:

O léxico é, antes de tudo, a soma dos conhecimentos alcançada por uma determinada comunidade histórico-linguística, a expressão global e coletiva do trabalho de criação conceitual que precede, acompanha e segue qualquer outra conquista humana. (apud CORDEIRO, 2018, p.17)

O conceito proposto por Alinei vai ao encontro das ideias de Biderman:

O léxico de uma língua natural constitui uma forma de se registrar o conhecimento do universo. Ao dar nomes aos seres e objetos, o homem os classifica simultaneamente. Assim, a nomeação da realidade pode ser considerada como a etapa primeira no percurso científico do espírito humano de conhecimento do universo. (2001, p.13) 
O processo de criação lexical descrito por Biderman é exatamente o rito seguido por Ripa. Esclarecemos que o léxico, no âmbito do trabalho proposto, será compreendido como produto de um registro cultural de um povo, o que abrange informações, significados e possíveis construções de uma língua que está sempre se expandindo, sendo ele uma ferramenta fundamental a ser utilizada na aquisição de conhecimentos (BIDERMAN, 1984).

Biderman (2001) esclarece que a Lexicologia e a Lexicografia são duas disciplinas tradicionais que enfocam o léxico como seu objeto de estudo, tratado de modos distintos, mas ambas têm a descrição do léxico como principal finalidade.

A Lexicologia é uma das Ciências do Léxico e uma das subáreas da Linguística que se dedica ao estudo científico do léxico de uma língua, sua natureza, etimologia, além das relações sistêmicas que o caracterizam. Compete à Lexicologia descrever as relações de significado que podem existir entre as palavras, as classes lexicais que as estruturam, estabelecer regras e explicar a relação existente entre os componentes lexicais. Além disso, esclarece casos nos quais a mesma sequência de sons, muitas vezes com a mesma ortografia, possui mais de um significado. Ademais, também analisa processos que podem levar a mudanças nos significados das palavras.

Como esclarece Abbade (2012, p. 142), “a Lexicologia, enquanto Ciência do Léxico, estuda as suas diversas relações com os outros sistemas da língua e, sobretudo, as relações internas do próprio léxico." Para que isso ocorra, a Lexicologia leva em consideração a estrutura da língua, o seu funcionamento e todas as mudanças que nela possam ocorrer. Tais aspectos são essenciais para se identificar a origem, determinar a forma ou aprender o significado do acervo lexical de uma língua e como esse acervo pode ser utilizado no interior de uma comunidade linguística.

A Lexicografia, por sua vez, se preocupa em estudar o repertório escrito e oral de uma língua. É comumente conhecida por ser a técnica de compilação e organização de dicionários, mas sua abrangência de atuação vai muito além, haja vista que desempenha diversas outras funções como organizar sistematicamente e realizar a descrição lexicográfica de obras, com o intuito principal de analisar a significação das palavras.

Ademais compete à Lexicografia a elaboração de técnicas que ordenam a coleta, a organização e a descrição do patrimônio lexical de uma língua, por meio das quais é possível construir obras lexicográficas de tipos variados. Destarte, é confiada à Lexicografia também a tarefa de explicar e fundamentar cientificamente as metodologias de análise empregadas.

A obra de Ripa se assemelha a uma obra lexicográfica, dados os seus critérios de elaboração. Como visto, o léxico de uma língua se constitui de todas as palavras que a compõem ou que a ela poderiam pertencer. Iconologia del Cavalier Cesare Ripa Perugino descreve, em forma de verbetes, como em um dicionário, o mundo onde Ripa vivia, com todos os seus costumes e modos típicos daquela época. Como visto, a obra de Ripa, assim como um dicionário, pode ser considerada um produto cultural de extrema relevância, pois revela interessantes aspectos relacionados à sociedade seiscentista da península itálica. 


\section{Procedimentos metodológicos}

Ao pensarmos os procedimentos metodológicos nos vêm em mente algumas questões: Quais os caminhos da melhor tradução? Quais decisões e desafios tradutológicos encontraremos ao longo do texto original? O desafio de traduzir uma obra do século XVII, a qual teve sua primeira edição em meados do século XVI, não é tão simples como o de traduzir um texto mais atual.

Durante a leitura da nona edição de 1645 , a primeira tarefa realizada foi a observação de letras e caracteres que já não existem nos textos atuais. Para isso, e contando com as noções de Paleografia, foi necessária a criação de uma tabela de correspondências para as atuais letras "L", "S" "T", "U", "V”, "Z", "R", que eram grafadas de maneira diferente, e ainda em alguns casos o "J", além do uso de alguns caracteres como o \&, já praticamente extinto em textos escritos na atualidade.

Para a tradução dos verbetes foram elaboradas algumas recomendações, como descrito abaixo:

i) Não ultrapassar o tamanho de uma página para a explicação de cada entrada, salvo em casos específicos. Essa escolha se deu em razão de o próprio Ripa não se delongar muito na explicação dos termos. Os elementos lexicais ocupam meia página e o conceito torna-se mais assertivo, breve e de fácil compreensão.

ii) Apresentar três ou mais iconologias, visto que Ripa coloca nessas unidades um número reduzido de imagens icônicas, com explicações claras e sucintas, podendo atrair com isso ainda mais a atenção do leitor atual.

iii) Incluir iconologias que se repetem na obra. A fim de explicar os outros itens, o autor faz uso de imagens simples e do cotidiano para melhor exemplificar o item proposto. Logo, a repetição de imagens denota o quanto as mesmas eram usadas no período e carregadas de simbologia.

iv) Utilizar um índice de relevância do item para a época. A sociedade do século XVI era muito pautada em conhecimentos de cultivo da terra e de arquitetura. Dessa forma, percebe-se a grande recorrência de termos destas áreas de conhecimento em toda a obra.

v) Elaborar uma lista de caracteres usados na tradução. Os caracteres "**, "( ) ), e "/” são um capricho de edição para facilitar a descrição linguística. O sinal de asterisco “*” em frente à palavra significa o uso de um sinônimo na tradução, ou que foi usada outra forma linguística para se conservar o sentido original da frase. Os caracteres entre parênteses "( )" indicam que eles foram inseridos na tradução e não estão presentes no texto original, indicando uma tradução por acréscimo, como aconselhado por Azenha (1999). A barra "/" separa o uso de duas palavras na tradução. Significa que a frase pode ser entendida com ambas, havendo similaridade entre os sentidos produzidos por cada uma.

vi) Acompanhar o item lexical com a imagem explicativa. Foram utilizadas em muitos itens lexicais as imagens explicativas correspondentes. Com base no detalhamento das imagens, a 
obra de Ripa pode ser lida inclusive por meio de seus textos não verbais, abrangendo, por assim dizer, o leitor analfabeto daquela época.

vii) Utilizar a tabela-guia, como ilustrado a seguir (Quadro 1). Ela serve para dar fluxo ao trabalho e facilitar a retomada dos itens de revisão, de forma a evitar que os tradutores se ocupem excessivamente com detalhes de tradução.

Quadro 1 - Tabela-guia

\begin{tabular}{|l|l|l|l|l|l|}
\hline Italiano & Português & Revisar? & Página & $\begin{array}{l}\text { Página } \\
\text { do livro } \\
\text { (original) }\end{array}$ & $\begin{array}{l}\text { Página do } \\
\text { arquivo PDF }\end{array}$ \\
\hline A & A & & & & \\
\hline Abondanza & Abundância & & 1,2 & & 17 \\
\hline $\begin{array}{l}\text { Abondanza } \\
\text { maritima }\end{array}$ & $\begin{array}{l}\text { Abundância } \\
\text { marítima }\end{array}$ & $\operatorname{sim}$ & 2 & & \\
\hline Academia & Academia & & 2 & & \\
\hline Accidia & $\begin{array}{l}\text { Preguiça } \\
\text { (Apatia) }\end{array}$ & Sim & 6 & & \\
\hline $\begin{array}{l}\text { Acutezza } \\
\text { d'ingegno }\end{array}$ & $\begin{array}{l}\text { Acuidade do } \\
\text { engenho }\end{array}$ & Sim & 7 & & \\
\hline
\end{tabular}

Fonte: Elaborado pelos autores (2019)

\subsection{Uso didático do texto de Ripa}

O objetivo didático mais importante aparece na associação da palavra com a imagem. Ripa insiste que deve haver uma qualidade alta entre o texto descrito com relação à imagem e que a qualidade da gravura da imagem deveria ter igual atenção. Para ele, muitas vezes há o problema da representação visual das imagens existentes, as quais não correspondem fielmente à descrição textual, por não ter o artista, na produção da xilogravura, prestado atenção aos detalhes alegóricos. Na falta de imagens para muitas alegorias descritas, Ripa indicava que o leitor as formasse a partir da descrição textual. Por conseguinte, foram criadas atividades didáticas com esse princípio. Existia uma exigência de Cesare Ripa tanto para a forma de descrição como para a qualidade do desenho ao qual o verbete se referia, de modo que, ao se descrever a forma, criava-se uma imagem mental que deveria equivaler ao conteúdo.

O uso de imagens para ensino do léxico, segundo Cantù (2011), favorece o interesse, possui flexibilidade de uso e pode ser usada em vários contextos. Scrivener (2001, p. 188) também 
afirma sobre a necessidade de outros estímulos para fixação de novos vocabulários: "Nosso trabalho não termina assim que os alunos conhecem um novo vocabulário; precisamos ajudá-los a praticar, aprender, armazenar, lembrar e usar o novo item"4.

A partir da tradução foram criadas duas atividades didáticas nessa linha. Na primeira atividade (Fig. 1), as palavras consideradas de pouca frequência, ou de difícil compreensão, foram destacadas em azul e associadas a imagens para que seja facilitada a leitura e compreensão do texto.

Figura 1 - Atividade didática 1

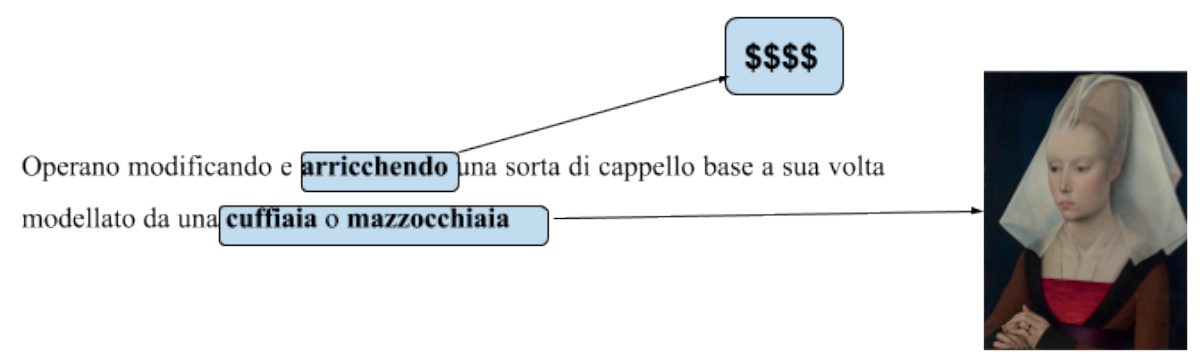

Fonte: Elaborado pelos autores (2019). Imagem: https://upload.wikimedia.org/wikipedia/ commons/3/36/Rogier_van_der_Weyden_Portrait_of_A_lady_C1460.jpg

A figura 2 apresenta um modelo de atividade didática em que é contada uma história na qual as palavras foram substituídas por imagens. Esse modelo de apresentação textual com a presença de ícones, além de proporcionar ludicidade à atividade ajudará os discentes a compreender melhor o conteúdo abordado.

$4 \quad$ Trecho original: "Our job does not finish as soon as students have first met some new lexis; we need to help them practise, learn, store, recall and use the items." 
Figura 2 - Modelo de atividade didática para o trabalho com o léxico
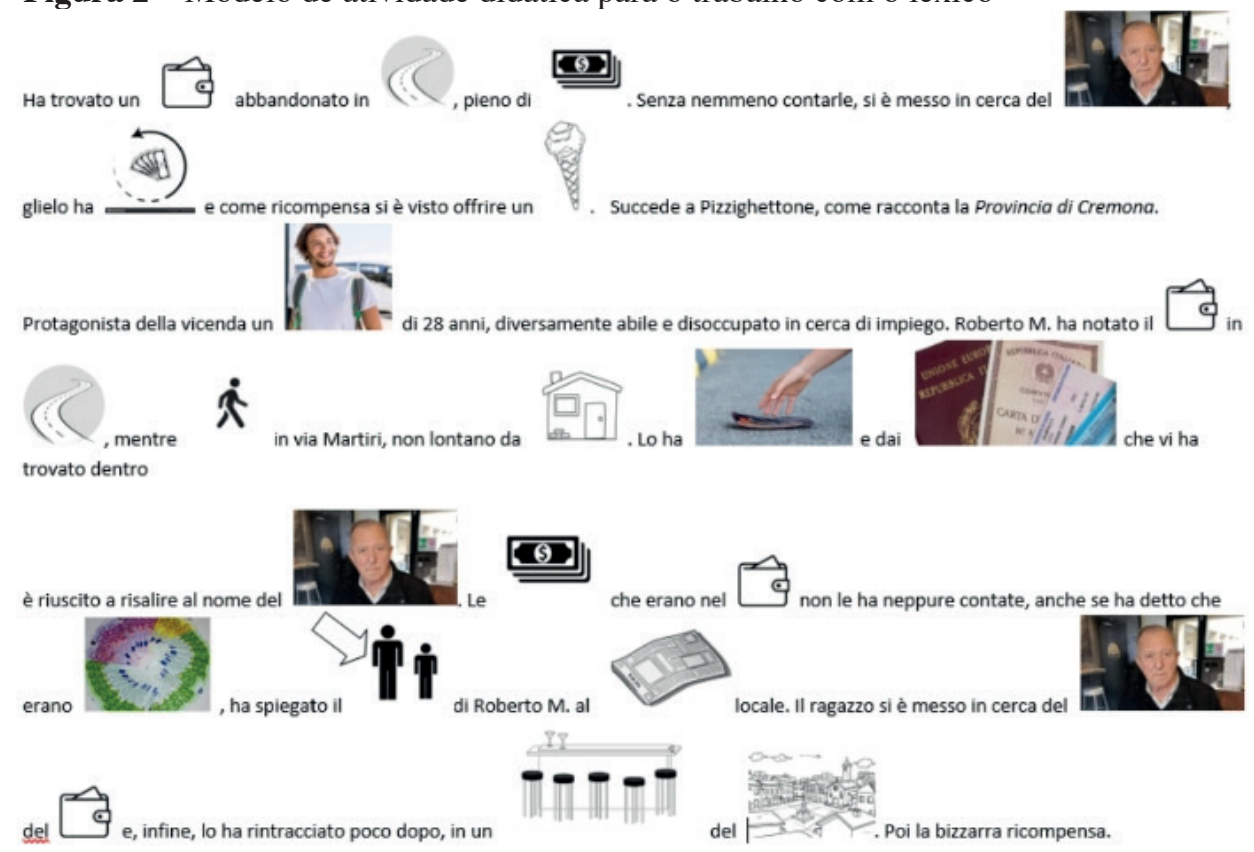

Fonte: Torresan (2019)

Por último, como trabalho mais descritivo, propõe-se a criação de fichas iconolexicográficas a partir das imagens de obras de arte e de seus autores, no qual é solicitado aos alunos que preencham os dados relacionados, como observado nas figuras 3 e 4 . 
Figura 3 - Ficha léxico-iconográfica do autor

\begin{tabular}{|l||l||}
\hline \\
\end{tabular}

Fonte: elaborado pelos autores (2019) 
Figura 4 - Ficha léxico-iconográfica da obra.

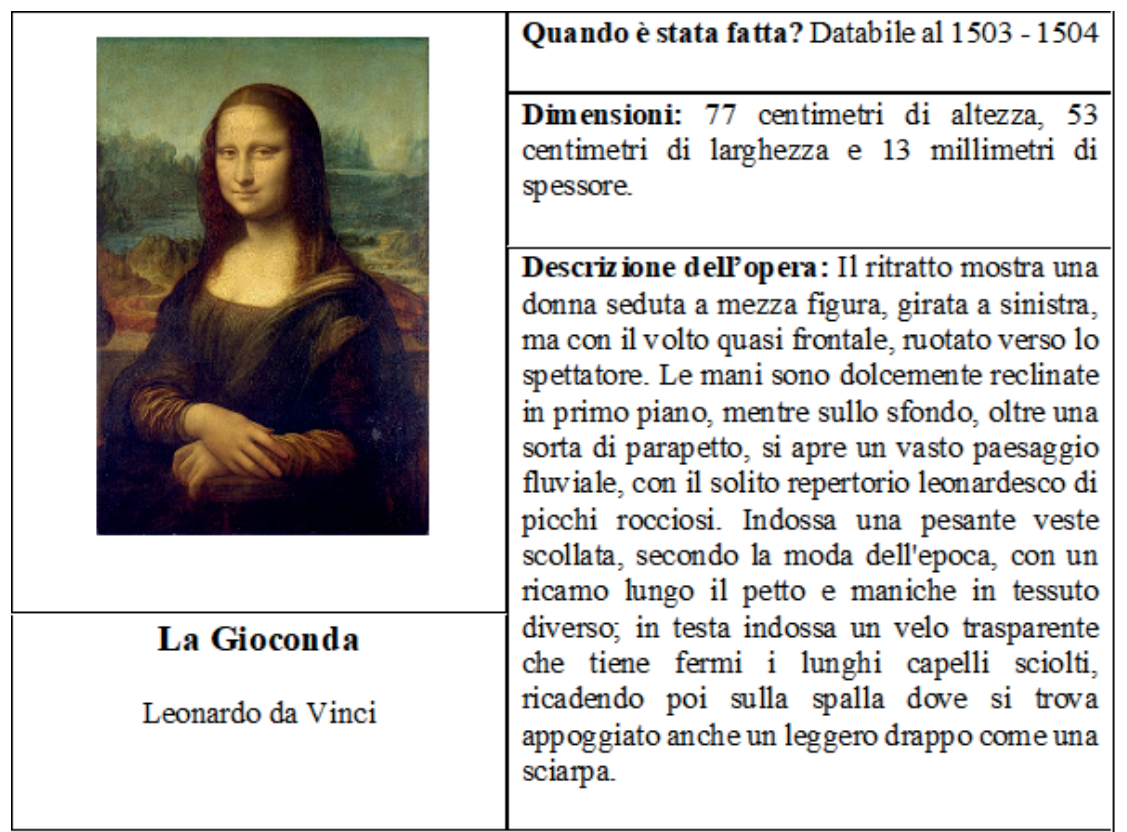

Fonte: elaborado pelos autores (2019) 


\section{Conclusão}

Ao se iniciar o trabalho de tradução, no segundo semestre de 2017, entre os meses de agosto e setembro, a barreira de quase cinco séculos de distância impossibilitava ainda a real percepção da importância do interessante e rico material que se tinha em mãos.

Sabe-se que o autor desenvolveu, na casa do cardeal Antonio Maria Salviati, o ofício de tagliatore. Além do acesso ao estudo propiciado pelo seu protetor, convívio com a sociedade culta e intelectual da época em Roma, tal trabalho permitiu a observação de Ripa que o conduziu à construção de seu léxico e sua acurada percepção de detalhes.

O estudo tradutório de texto escrito em língua "italiana" do século XVI exigiu detalhada observação, acuidade visual e textual, encontrando elementos de linguagens diversas, protagonistas concorrentes que visualmente constroem e completam o sentido intencional do autor. Seu processo e construção metodológica podem ser colocados como um modelo de desenvolvimento do ensino e pesquisa no campo da Moda, tendo como eixo desafiador sua característica transdisciplinar.

$\mathrm{O}$ acesso ao seu pensamento nos permite realizar uma leitura transversal entre imagem e texto, sendo as imagens elementos de inestimável importância, por sua possibilidade de aproximação ou distanciamento com outras tantas imagens ilustrativas diversas encontradas nas inúmeras publicações do texto.

Em todo o processo é produzida uma verificação da história da Arte e da Cultura, no percurso temporal proposto, época em que os objetos de poder foram multiplicados, sendo associados aos sentidos e culturas criadas por eles.

Devemos estar atentos para dois conceitos: tradição e inovação, visto que a história da Arte é construída por processos. Certos fazeres artísticos estão, desde a mais remota história da humanidade, arraigados na tradição e, nesse sentido, seguem um rito do fazer, o qual se mantém imutável por longos períodos. No entanto, em alguns momentos da história do fazer artístico, estes ritos foram marcados por desenvolvimentos e contradições. É nestes eventos que conseguimos perceber como o fazer artístico supera a técnica e como a tradição é rompida, repensada, substituída:

[...] Uma espécie de proxêmica, ciência das distâncias, distinguia as diferentes categorias sociais graças ao comprimento da cauda, à largura das mangas, ao tecido etc. Em uma cidade em que nem todos se conheciam, isso servia como uma espécie de mapa para se orientar possibilitado pela moda. (MUZZARELLI, 2014, p.56) ${ }^{5}$

É neste caminho que podemos inserir os objetos culturais históricos como livros abertos, através dos quais podemos decodificar o passado, fazer a leitura estabelecendo diálogos horizontalmente coerentes ao tempo do objeto, bem como propor diálogos verticalizados, perpendiculares ao correr do tempo, perpassando os séculos, as culturas, as cidades, os espaços geográficos, os fazeres artísticos da história da humanidade, voltando às intenções de Ripa, que propôs

$5 \quad$ "Una sorta di prossemica, scienza delle distanze, distingueva le diverse categorie sociali grazie alla lunghezza dello strascico, alla larghezza delle maniche, al tessuto etc. In città in cui non tutti conoscono tutti serviva una sorta di mappa per orientarsi e la moda la fornì." 
os conhecimentos dos conceitos por meio das imagens simbólicas, aproximando a boa e eficaz escrita às imagens que traduzem conceitos que conduziram a sociedade do século XVI ao século XVIII, quando mudanças significativas moldaram o final da época moderna e o início da modernidade. 


\section{Referências}

ABBADE, C. M. de S. Lexicologia social: a lexemática e a teoria dos campos lexicais. In: ISQUERDO, A. N.; SEABRA, M. C. T. C. de. (Orgs.). As ciências do léxico: lexicologia, lexicografia, terminologia. Campo Grande: UFMS, 2012, v. 6, p. 141-161.

CANTÙ, S. Il Potere dell'immagine nel processo di insegnamento-apprendimento. Dissertação (Master in Insegnamento nella Scuola Media) - Scuola Universitaria Professionale della Svizzera Italiana, Lugano, 31 f., 2011. Disponível em: https://www.supsi.ch/dfa/dms/dfa/docs/master/20120530_661758_ MASM_Cantu_Sabrina.pdf. Acesso em 16/12/2020.

AZENHA Jr., J. Tradução técnica e condicionantes culturais: primeiros passos para um registro integrado. São Paulo: Humanitas - FFLCH/USP, 1999.

BERWANGER, A. R.; LEAL, J. E. F. Noções de Paleografia e de Diplomática. 4.ed. Santa Maria: UFSM, 2012.

BIDERMAN, M. T. C. As ciências do léxico. In: OLIVEIRA, A. M. P. P.; ISQUERDO, A. N. (Orgs.). As ciências do léxico: lexicologia, lexicografia, terminologia. 2. ed. Campo Grande, MS: UFMS, 2001.

. A ciência da lexicografia. ALFA: Revista de Linguística. Universidade Estadual Paulista. n.28, 1984, p. 1-26. Disponível em: https://periodicos.fclar.unesp.br/alfa/article/view/3676. Acesso em: $06 / 12 / 2020$.

CORDEIRO, M. J. Pietro Bembo: um literato na vanguarda do seu tempo. In: Jorge, W. J. (org.). Novos olhares para a Linguística e Literatura. Maringá: Uniedusul Editora, 2019, p. 86-94. Disponível em: https://www.uniedusul.com.br/wp-content/uploads/2020/05/LIVRO-NOVOS-OLHARES-PARA-ALINGU\%C3\%8DSTICA.pdf. Acesso em: 06/12/2020.

MOUNIN, G. Os problemas teóricos da tradução. Tradução H. de Lima Dantas. São Paulo: Cultrix, 1975.

MUZZARELLI, M. G. Breve storia della moda in Italia. Bolonha: Il Mulino, 2014.

PERUGINO, C. R. Iconologia del Cavaliere Ripa. Venezia: 1593.

PERUGINO, C. R. Iconologia del Cavaliere Ripa. Venezia: 1645.

SCRIVENER, J. Learning Teaching. Oxford: Macmillan-Heinemann, 2011.

Recebido em: 24/08/2020

Aprovado em: 17/12/2020 